\title{
PEDAGOGY INTHE NURSERY: Establishing practitioner partnerships in high-quality long day care programs
}

\section{Kym Macfarlane \\ Karen Noble \\ Jennifer Cartmel}

Griffith University, Logan Campus

One of the most significant societal changes over the past few decades has been the growing number of women in the paid work force. As a direct result of this sociological phenomenon, childcare centres have been providing long day care for vastly increasing numbers of very young children. The speed of this change has created a societal dilemma regarding the level of training required to prepare practitioners for such important pedagogical work.

Traditional approaches to the training and preparation of practitioners for work in this field do not always highlight the significance of the important relationship early childhood education and care practitioners have with very young children, or respond to current conceptualisations of children and families and the contexts in which they live (Dahlberg, Moss \& Pence, 2002; Moss, 2003). This paper takes issue with these points by exploring an alternative approach to the preparation of practitioners for work in this field. The use of Learning Circles as a conceptual tool is examined as an alternative response, aimed at developing a concentrated pedagogical process by which undergraduates explore the links between theory and effective practice.

\section{Introduction}

In what does it consist, if not in the endeavour to know how and to what extent it might be possible to think differently, instead of legitimating what is already known. [Thought] is entitled to explore what might be changed, through the practice of a knowledge that is foreign to it. (Foucault, 1985, p. 9)

In most fields of discipline it is traditional understandings and principles that inform practice. What is not commonly understood, however, is that sometimes adherence to these traditional understandings can actually impede and delimit the practice of professionals rather than positively influencing that process. As is highlighted in the above quote, the importance of 'thinking otherwise' (Foucault, 1984; McWilliam, 1998) about practice cannot be overstated. These points relate to the field of early childhood education and care (ECEC). For, while much has been written about the tensions that exist in Australian early childhood education, care, policy and practice (Fleer, 2000; Organisation for Economic Cooperation and Development [OECD], 2001; Press \& Hayes, 2000), there is a further need to examine closely the knowledge base, policies and practices of early childhood education and care in order to reflect upon the appropriateness of practitioner preparation. Such endeavours may provide an approach to structures and practices that allow for a seamless transition for ECEC service reform as well as practitioner preparedness (Noble, 2003). This is certainly true of practice in relation to work with infants and toddlers.

Historically, the experiences of infants and toddlers in formal long day care settings have been a point of controversy (Petrie, 1988; Brennan, 1994; 1998). An effect of this controversy has been that childcare programs for infants and toddlers are not cohesive. because of the disparity that exists in practitioner preparation programs (Moss, 2003). These differences can be due to adherence to traditional, rather than contemporary, understandings of childhood, mothering and institutionalised care. Additionally, the debate over the care and education of young children has caused divisions in society, even between women (Brennan, 1994; 1998), as the uncertainty surrounding the practices used when working with infants and toddlers highlights parental and societal insecurity. Such issues inhibit progress in the development of high-quality 
programs for these young children. As we move further into the 21 st century, and experience a greater concentration of women returning to the work force, it is imperative that some cohesive practice in the care and education of infants and toddlers be adopted as more and more of these young children move into group care settings. Research indicates that the quality of infant and toddler programs, and the quality of the practitioners implementing them, impacts significantly on the development and further education of the children who participate in them (OECD, 2001; Press \& Hayes, 2000). High-quality long day care programs are vital to the enhanced development of infants and toddlers, and consequently the training of effective practitioners in this sector is vital (Dahlberg, Moss \& Pence, 2002; Moss, 2003; Commonwealth Department of Family and Community Services [FaCS], 2003).

\section{Child care in the 21 st century}

As has previously been stated, the social context in which ECEC practitioners presently operate reflects marked changes to the very fabric of society in general. According to Tayler, 'the changing social world of Australia in the late 1990s should be an ecological barometer for early childhood education course developers' (1997, p. 7). Fleer (2000) further supports this stance, stating that this is a critical time for childcare services in Australia. As out-of-home care for the very young increases, practitioners must facilitate development and learning for infants and toddlers from increasingly diverse backgrounds. On the one hand, ECEC practitioner preparation programs must ensure that they produce practitioners who are able to respond to present demands across the sector, while on the other hand also producing practitioners who are able to critically evaluate and reflect upon current and future trends that may influence this particular field of work, both theoretically and practically.

This paper calls for a greater emphasis on research into infant and toddler child care experiences in order that opportunities for reforming training and education for practitioners who operate in this particular sector of the ECEC field are highlighted. Practitioners working in this sector of child care-aside from developing, implementing and evaluating high-quality programs for infants and toddlers-must also develop the skills of responding to other social influences that impact upon young children and their families. Statistically, the average age of the Australian mother is increasing (Australian Bureau of Statistics [ABS], 2002), while the percentage of grandparents caring for young children is decreasing ( $A B S, 2002$ ). These statistics have ramifications for the way the ECEC sector caters for the changing needs of young children and their families.

As knowledge of very young children grows, so too does an awareness of the first years of life, particularly in terms of the enormous cognitive, emotional and social developments that take place. The caregiving styles and interactions of practitioners working with very young children impact upon these developments in significant ways (Greenman \& Stonehouse, 1999; Hutchins, 1995; Hutchins \& Sims, 1999). Evidence from the latest brain development research regarding the protective functions of sensitive, nurturing care in the early years supports the argument for the development of high-quality children's services for this particular age group (Catherwood, 2000). Thus, children under three years of age require specialised approaches in formal ECEC services, tailored to suit their changing needs.

Clearly then, further attention needs to be given to the development of high-quality programs for infants and toddlers and, as a result, high-quality practitioner preparation programs. It becomes imperative to ensure that new early childhood practitioners develop skills to cater for the intricacies of working with very young children and their families. As such, undergraduate early childhood practitioners need to be provided opportunities to develop such skills, including skills of critical reflection. The development of these skills should not be perceived to be an innate ability but, rather, needs to be carefully scaffolded in order that such practitioners working with infants and toddlers feel empowered in their endeavours to develop quality practices that foster effective relationships with young children and their families. Consequently, undergraduate programs must respond to changing contexts and demands in the workplace by providing multi-skilled practitioners who are flexible and innovative in their approaches to infant and toddler care and education.

\section{Reconceptualising practitioner preparation}

The project presented for discussion in this paper aims to:

- adopt strategies for the development of highquality programs for infants and toddlers;

- engage students in the process of reconceptualising care and education of young children;

- develop in students a greater understanding of how care and education for infants and toddlers are inextricably linked; 
- utilise the practicum experience of students from the Bachelor of Human Services (Child and Family Studies), Bachelor of Human Services/Bachelor of Education (Primary), involving them in high-quality childcare programs in Logan-the reasons for highlighting needs in the Logan area will become apparent later in this paper-and the surrounding areas, where they can access already established vehicles of effective practice;

- enhance and develop high-quality practicum learning experiences for students; and

- develop closer links with community agencies leading to enhanced learning opportunities for Griffith University graduates, the wider early childhood field and young children.

This reconceptualisation of the practicum experience, using the Learning Circle approach (Bishop \& Gibson, 1997; Centre of Excellence for Child and Youth Centred Prairie Communities, 2003; Gibson, 1998; Karasi \& Segar, 2000; Professional Development Network, 2003) for the targeted student group, will:

- provide a more student-centred focus;

- encourage a flexible approach to teaching and learning;

- initiate and lead enterprise within the early childhood field;

- develop within students the ability to analyse and critically evaluate theory and practice within the field; and

- utilise many aspects of generic skill development in students, including problem solving, working effectively as a member of a team, reflection, evaluation, assessment and participation in decision-making processes.

\section{Circles of change}

Learning Circles are used in this project as the tools for promoting critical reflection amongst practitioners. Learning Circles are self-managed learning groups, built on the fundamental principles of adult learning. The best adult learning encourages and supports the critical reflection on what we think we already know (Crombe, 1999; Sumsion, 2003). In this way, Learning Circles have proven a practical and effective method of learning and supporting change. They are a way for students to form new understandings with regard to important issues, in their own time (Barob, MaKinster,
Moore \& Cunningham, 2001; Gibson, 1998; Karasi \& Segar, 2000). The Learning Circle approach has been a predominant part of adult education, especially in Scandinavia (Crombe, 1999). Such an approach is understood as democracy in action, as it encourages all views to be expressed and explores various merits. An effective Learning Circle can empower its members to act as they see fit, on the basis of the new knowledge this process generates.

The importance of this Learning Circle approach to the preparation of practitioners in this field cannot be overestimated. In recent times there has been a growing emphasis on reflective practice as a means of assisting professionals to respond to the complex nature of the workplace (Moss, 2000; Patterson \& Sumsion, 1996). Many researchers cite reflection or reflexivity as a means of objectively examining methods of practice and policy formation in order to instigate positive change (Ebbeck \& Waniganayake, 2003; Johansson, 2003; Mayall, 1994; 1999). The Learning Circle approach has been chosen and adopted here in order to maximise opportunities for students to reflect upon the practicum experience, thereby further enhancing the learning outcomes achieved through practicum and the development of the generic skills necessary to work across many different programs. Learning Circles provide self-directed learning, with the learning occurring through shared inquiry and dialogue. The decision to use Learning Circles was based on the need to have effective debriefing processes and time for highquality critical reflection, particularly with an increasing number of students participating in the program.

In relation to work with infants and toddlers, a Learning Circle approach comprising practitioners in the field, students and academics will create space for shared experiences to generate new epistemological understandings, which will inform the practice of all those involved. Additionally, the process of critical reflection will be enhanced. For the purpose of this exercise, critical reflection is understood to be the ability to reflect honestly on one's practice in a manner that allows multiple perspectives and approaches to inform the work that is done. Critical reflection differs from reflective practice that for early childhood practitioners has often been informed by romantic notions of idealistic approaches to working with young children (Sumsion, 2003). These romantic notions of practice do not withstand the complexity, uncertainty and insecurity of working with young children and their families in the current context (Hulqvist \& Dahlberg, 
2001; Jenks, 1996a; 1996b; Lyotard, 1984). Thus, critical reflection needs to address this dilemma, allowing multiple perspectives and understandings to be examined and employed by practitioners in the field. Sumsion (2003) understands critical reflection as a discursive project using Phelan's argument, which contests that preservice teachers should 'be exposed to a wider range of discourses than are traditionally sanctioned by teacher education programs' (Sumsion, 2003, p. 83). Furthermore, Phelan states:

... [practitioner] education needs to become a discursive project. There is no escaping discourse. There is no escaping that language/discourse constitutes experience generally, and our experience of place specifically. [Practitioner] educators may need to consider how we can help prospective practitioners to recognize the multiple discourses that shape and often restrict their thinking about experience and place (cited in Sumsion, 2003, p. 19).

Thus, if critical reflection can be effectively taught to preservice practitioners, it can act as a means of deconstructing traditional grand narratives and approaches that may delimit possibilities for wellinformed and responsive practice, particularly in relation to work with young children. In order to achieve this level of critical reflective ability, undergraduate early childhood practitioners need to be provided opportunities to develop the necessary skills for high-quality practice, including the skills of critical reflection, and the Learning Circle approach is a proven method of doing so.

\section{The project conceptualised}

In an effort to take up the challenge of promoting a contemporary approach to the training of practitioners for work with very young children, this new practicum project has been conceptualised in an attempt to redress some of the aforementioned issues. This project has developed from national and local pressures. It is a response to the challenges preempted in the Child Care: Beyond 2001 document (Commonwealth Child Care Advisory Council [CCCAC], 200I), which cites the need for a greater valuing of people who work in the children's services sector. Locally, this project developed in response to requests from a children's services industry reference group in the Logan area, where issues relating to the juxtaposition of the specialised nature of practice with infants and toddlers and the preparation of practitioners for the workplace were highlighted
(Minutes, Logan TAFE Industry Advisory Committee Child Studies, November, 2002).

The Logan TAFE Industry Advisory Committee noted that the historical context of child care, traditional conceptualisations of mothering, and a proliferation of childcare places in the Logan area inhibited the quality of practices and preparation of practitioners for work in long day care centres, particularly in the infant and toddler area. Negative media attention and questionable industrial practices in Queensland (Burton \& Lyons, 2000) have had the effect of downgrading the importance of such programs, leading to uncertainty about the suitability of long day care for infants and toddlers and ambivalence towards financial support of quality enhancement. Thus, the least-qualified practitioners often staff infant and toddler programs (National Agenda for Early Childhood, 2003). This is particularly the case in Queensland, especially in the Logan area, where a proliferation of centres was established following the Keating Labor Government's childcare initiatives in 1996.

The effects of the aforementioned issues, coupled with the high levels of responsibility and low wages of practitioners working in infant and toddler areas, causes levels of morale to be poor and levels of stress to be heightened (Sims, Hutchins \& Dimovich, 2002). Additionally, staff employed in these positions are often young and ill-equipped to cope with the demands of the infant and toddler rooms (Sims, Hutchins \& Dimovich, 2002). These factors highlight concerns about quality in infant and toddler practice and the level of preparedness in practitioners. Staff who work with infants and toddlers require specialised training and support to ensure that the particular challenges can be successfully overcome.

Thus, implementing the Learning Circle approach as a teaching tool in the previously mentioned programs will provide enhanced skill development for both the practitioners in the field in Logan and the emerging practitioners. This will better prepare them for work in this challenging geographical area and add depth to the practice of those already working in the field. This will occur through the democratic approaches of the Learning Circle and the promotion of honest and critical reflection of the practice of those concerned. Consequently, an improvement in quality in infant and toddler programs in this area is more likely, as practitioners and students learn from each other, by exploring multiple understandings of early childhood 
education and care practice in a safe environment. While this particular project is localised, the issues pertaining to its implementation are far-reaching. Evidence of the need for highly-trained professionals in the infant and toddler area is abundant (Berk, 200I; CCCAC, 2001; Cameron \& Moss, 2002; Edwards, Gandini \& Forman, 1998; Elkind, 1988; Greenman \& Stonehouse, 1999; Hendrick, 1996; Hutchins \& Sims, 1999; Misko, 2003; Moss, 2000; Moss \& Petrie, 2002). Moreover, it is becoming clear that the needs of very young children in the long day care setting require effective responses from multi-talented practitioners. This is highlighted by the CCCAC when they state, 'The goal [of high-quality training, education and professional development] should be to achieve an integrated approach to training teachers and carers. Specific strategies require collaboration between all key stakeholders' (2001, p. 12). Integrated understandings of prospective practitioners, which are informed by those already working in high-quality centres of this type, become paramount. Furthermore, building community partnerships and professional networks that enhance the skills and knowledge base of students looking to work in the children's services sector becomes an important factor and an innovative approach to the training of practitioners for the ECEC field.

Consequently, this project aims to focus on developing a curriculum for practicum, which responds to the changing context in the children's services sector and provides a positive initial experience for students in the field (Cameron \& Moss, 2002; CCCAC, 2001; Moss \& Petrie, 2002; OECD, 2001). The Learning Circle approach aims to allow a concentrated pedagogical process that will produce a more conscious learner, who has a flexible approach to service delivery and is able to apply theoretical knowledge to real situations involving the care and education of infants and toddlers. The project also aims to produce practitioners who can provide high-quality experiences for infants and toddlers and who can articulate these practices to families and the community, which will in turn impact on the provision of such programs as a whole.

\section{The program in place}

The Learning Circle approach will be conducted onsite at local childcare centres. Six high-quality childcare centres, with highly trained and experienced staff and high-quality programs for infants and toddlers, have been chosen to participate in the project. Each centre will provide placement opportunities for eight students during two set periods throughout the semester. This means that a total of 48 students can be catered for. Following on from the compulsory six individual visits prior to the block practicum experience, students will be required to attend their placement for three days per week for three weeks. Three hours on one designated day each week will be set aside for participation in the Learning Circle. During this time, childcare centre staff and Child and Family Studies lecturers will guide students in the processes of critical reflection, evaluation, assessment and debriefing of the practicum experience. Students will be encouraged to reflect honestly on the processes of their experience, confronting issues and highlighting best practice. This critically reflective process will occur in the presence of field practitioners who can give perspective to significant issues and comment on what high-quality practice actually looks like.

It is envisaged that the Learning Circle process will allow students to form deeper understandings of practice with infants and toddlers in the long day care setting, recognising that high-quality care and education programs are possible and modifying their practices to achieve these goals. The students will become more self-reflective, meta-cognitively aware and self-directed learners as a result of accessing information, experience and mentoring from professional staff and lecturers, in a small group setting not normally available to them in traditional practicum experiences. As such, the Child and Family Studies team who conceptualised this project is working towards producing graduates who are problem-solvers, decision-makers, communicators, critical thinkers, and positive team members with awareness of effective interpersonal skills and group facilitation processes and the role of lifelong learning in their professional growth and development.

In order to ensure that this approach enhances practice, significant evaluation of, and reflection on, the process is necessary. Qualitative data will be progressively collected throughout the project by using videotape, audiotape and written evaluations. Emerging issues which may require consideration will be further evaluated through discussion, observation and analysis of the written documentation. At the end of the process, students will be required to hand in a reflective journal as part of the assessment for the course. With permission of the students, data will be collected from these journals and qualitatively analysed by the Child and Family Studies staff. Additionally, students and childcare centre staff will be asked to 
complete evaluations of the project, which will be quantitatively and qualitatively analysed by the use of computer programs. Categories for analysis of data will be constructed from the aims of the project, which were previously outlined.

\section{Traditional practice: Does it go far enough?}

Traditional programs of practicum for ECEC practitioners tend to extend opportunities to develop isolated sets of knowledge, skills and abilities, and to apply these during blocks of practice (Corrie \& Maloney, 1996). Within such a framework, it is unlikely that sound reflective practice is present, as the isolation of the practitioners limits the dialogue pertaining to the practicum. As practitioners' knowledge 'is constructed out of a dialogic relationship that exerts a dynamic and reciprocal influence between theory and practice' (Corrie \& Maloney, 1996, p. 71), these traditional programs lack the necessary substance to provide students with effective and quality experiences. However, it is not the intention in this work to demonise traditional programs as a whole. The Child and Family Studies team from the School of Human Services merely wish to point out that traditional practice may not be adequately preparing practitioners for the complexities of the current ECEC working context, particularly in relation to infants and toddlers. As such, the Learning Circle approach offers an opportunity to further evaluate traditional practice against a new model that offers greater opportunities for mentoring and critical reflection. The Learning Circle approach, while designed in this case specifically for practitioners working with infants and toddlers, has generalisability to other areas of practice in the children's services sector because its underlying principles are relevant to the care and education of children from birth to 12 years and are fundamental in the adult lifelong learning process.

\section{Concluding thoughts}

It is envisaged that this Learning Circle approach will vastly improve the ability of students to successfully navigate the theory and practice nexus, essential for the development of practitioners able to negotiate the demands of complex situations. As the move towards integrated programs (Dahlberg, Moss \& Pence, 2002; Moss, 2003; Tayler, 1997) is gaining momentum, the necessity for new ways of dealing with practice issues for children and families is vital. Research is clear in stating that reflective practitioners are more able to cope with the complex changes, insecurities and technological advances symptomatic of the postmodern condition (Lyotard, 1984). Insights gained from involvement in this study further reinforce the importance of recognising the complex nature of personal and professional growth of early childhood practitioners, particularly in the context of philosophical and pedagogical challenges impacting upon a rapidly changing field. Such processes as outlined above ignite the curiosity of the practitioners, encouraging them to thoroughly investigate multiple ways of quality practice.

\section{References}

Australian Bureau of Statistics (2002). Labourforce, Austrolia. Australian Bureau of Statistics. Retrieved 20 May 2003. <http://www.abs.gov.au>.

Barob, S. A., MaKinster, J. G., \& Cunningham, D. J. (2001). Designing and building an on-line community: The struggle to support sociability in the inquiry learning forum. Educational Technology, Research and Development, 49(4), 71-95.

Berk, L. (2001). Development through the lifespan. Boston, MA: Allyn \& Bacon.

Bishop, M., \& Gibson, G. (1997). Community dialogue: The power of a learning circle. Community Quarterly, 45, 27-33.

Brennan, D. (1994). The politics of Australian child care: From philanthropy to feminism. Melbourne: Cambridge University Press.

Brennan, D. (1998). The politics of Australian child care: Philanthropy to feminism and beyond. Melbourne: Cambridge University Press.

Burton, J., \& Lyons, M. (2000). When does an early childhood teacher teach? In J. Hayden (Ed.), Landscapes in early childhood education (pp. 271-290). New York: Peter Lang.

Cameron, C., \& Moss, P. (2002). The child care workforce: Current conditions and future directions. Critical Social Policy, 22(4). 572-595

Catherwood, D. (2000). New views on the young brain: Offerings from developmental psychology to early childhood education. Contemporary Issues in Early Childhood, I(1), 23-35.

Centre for Excellence for Child and Youth Centred Prairie Communities. Retrieved 5 August 2003.

<http://www.uwinnipeg.ca/ ius/coe>

Commonwealth Child Care Advisory Council (2001). Child care: Beyond 200I, a report to the Minister for Fomily and Community Services. Canberra: Australian Government.

Commonwealth Department of Family and Community Services (2003). National Agenda for Early Childhood. Retrieved 28 March 2004. <http://www.facs.gov.au>.

Corrie, L., \& Maloney, C. (1996). An alternative school based field experience program for 3 rd year teacher education students. Paper presented at the Australian Research in Early Childhood Conference, University of Canberra. Canberra.

Crombe, A. (1999). Learning Circles: Organising, facilitating. participating. Adult Learning Australia, 1-8.

Dahlberg, G., Moss, P., \& Pence, A. (2002). Beyond quality in early childhood education and care: Postmodern perspectives. London: Routledge Falmer. 
Ebbeck, M.. \& Waniganayake, M. (2003). Early childhood professionals: Leading today and tomorrow. NSW: MacLennan \& Petty.

Edwards, C., Gandini, L., \& Forman, G. (Eds.) (1998). The hundred languages of children: The Reggio Emilia approach to early childhood education. New Jersey: Ablex.

Elkind, D. (1988). The hurried child: Growing up too fost too soon. Massachusetts: Addison Wesley.

Fleer. M. (2000). An early childhood research agenda: Voices from the field. Canberra: J. S. McMillan.

Foucault, M. (1984). Nietzsche, genealogy and history. In P. Rabinow (Ed.). The Foucault Reader (pp. 10I-I20). London: Penguin.

Foucault, M. (1985). The use of pleosure: Volume 2 of the history of sexuality. New York: Pantheon.

Gibson, G. (1998). A guide for local government on the theory and practice of learning circles. Canberra: Australian Centre for Regional and Local Government Studies, University of Canberra.

Greenman. J.. \& Stonehouse, A. (1999). Prime times: A handbook for excellence in infant and toddler program. Melbourne: Addison Wesley Longman.

Hendrick, J. (1996). The whole child: Developmental education for the early years. New Jersey: Prentice Hall.

Hultqvist, K., \& Dahlberg, G. (200I). Governing the child in the new millennium. New York: Routledge Falmer.

Hutchins, T. (1995). Babies need more than minding: Planning programs for babies and toddlers in group settings. Watson. ACT: Australian Early Childhood Association.

Hutchins, M., \& Sims, T. (1999). Programming and planning for infonts and toddlers: An ecological approach. Sydney: Prentice Hall.

Jenks, C. (1996a). Childhood. London: Routledge.

Jenks, C. (1996b). The postmodern child. In J. Brannen \& M. O'Brien (Eds.). Children in fomilies: Research and policy (pp. 13-25). London: Falmer.

Johansson, M. (2003). Will there be any preschool teachers in the future? A comment on the present Swedish reform of teacher education. Paper presented at the 13th European Eorly Childhood Education Research Association Conference, University of Strathclyde, Glasgow.

Karasi, M., \& Segar, C. (2000). Learning Circles: An innovative tool for workplace learning for EL teachers. Paper presented at 35th SEAMEO RELC Seminar, Singapore, 17-19 April.

Logan TAFE Industry Advisory Committee (2002). Minutes of Logan TAFE Industry Advisory Committee - Child Studies, November.

Lyotard, J. F. (1984). The postmodern condition. Manchester: Manchester University Press.

Mayall, B. (1994). Children's childhoods: Observed and experienced. London: Falmer.

Mayall, B. (1999). Critical issues in social research. Philadelphia: Open University Press.

McWilliam, E. (1998). Created thinking in teacher education: The appeal of non-stupid optimism. Paper presented at the Australion Teacher Education Association Annual Conference, Melbourne, 6 July.

Misko, J. (2003). Training and employment in the Queensland child care and early childhood education sector. Brisbane: National Centre for Vocational Education Research.
Moss, P. (2000). Training of early childhood education and care staff. International Journal of Educational Reseorch, 38, 31-53.

Moss, P. (2003). Getting beyond childcare: Reflections on recent policy and future possibilities. In J. Brannen \& P. Moss (Eds.), Rethinking children's care (pp. 25-44). Buckingham: Open University Press.

Moss, P., \& Petrie, P. (2002). From children's services to children's spaces. London: Routledge Falmer.

Noble, K. (2003). Graduate programs for students working in the ECEC sector. Refereed paper submitted to the New Zealand Association of Research in Education/Australian Association of Research in Education Conference, Auckland, New Zealand, 29 November - 4 December.

Organisation for Economic Cooperation and Development (2001). Starting strong: Early childhood and care. Paris: OECD.

Patterson, C., \& Sumsion, J. (1996). Linking theory and practice in early childhood teacher education. Paper presented at the Australian Research in Early Childhood Education Symposium, University of Canberra.

Petrie, A. (1988). Education and care: The false dichotomy. Australian Journal of Early Childhood, 13(3). 26-30.

Press, F., \& Hayes, A. (2000). OECD thematic review of early childhood education and care policy. Canberra: Department of Family and Community Services.

Sims, M., Hutchins, T., \& Diminovich, C. (2002). Juniors minding junior: The experiences of junior childcare workers. Contemporary Issues in Early Childhood, 3(1), 117-131.

Sumsion, J. (2003). Rereading metaphors as cultural texts: A case study of early childhood teacher attrition. The Australion Educational Researcher, 30(3), 67-88.

Tayler, C. (1997). Early childhood teacher education: Social dynamism - cultural vacuum? Paper presented at the Australion Teacher Education Association Conference, Central Queensland University, Rockhampton. 